\section{ORAL PATHOLOGY}

\section{Pathologically significant periocoronal lesions in adults: histopathological evaluation}

Curran AE, Damm DD et al. J Oral Maxillofac Surg 2002; 60: 613-617

One third of all biopsies adjacent to crowns of unerupted teeth had significant lesions.

Over a 6 year period, 2646 pericoronal lesions were biopsied when impacted teeth were removed from patients aged 18-89 yrs. Over $90 \%$ were from third molars, and most of the others were from canines. The biopsies constituted $7.6 \%$ of all oral biopsies sent to a US university laboratory.

Most reports (67\%) were of follicular tissue. Lesions diagnosed were: dentigerous cyst (28\%), dentigerous cyst with mucous cell prosoplasia (3\%), odontogenic keratocyst (2.7\%), odontoma (0.7\%), ameloblastoma (0.5\%), calcifying odontogenic cyst (0.23\%), carcinoma (0.23) and odontogenic myxoma (0.04\%).

From the 5th decade onwards, about half the biopsies were of pathological lesions. Dentigerous cyst was the commonest lesion up to age 70, but other lesions were more frequent later. A following critical discussion states that the findings justify histopathological examination of perifollicular tissue from all impacted teeth removed after age 30 .

\section{IMPLANT PROSTHODONTICS}

\section{Five years of aftercare of implant-retained mandibular overdentures and conventional dentures}

Visser A, Geertman ME et al. J Oral Rehabil 2002; 29: 113-120

Endosseous implants were substantially better than the transmandibular implant system.

In 2 centres in the Netherlands, 222 patients (6\% had dropped out) were followed up after 6 categories of complete prosthodontic treatment for severely resorbed mandibular ridges. Most of the patients were also evaluated on a 5 point scale for comparing implants.

During 5 years' follow-up, in patients with mandibles of 8-15 mm height, implant loss was 5\% for 57 overdentures on 2 endosseous implants, and $29 \%$ for 27 with transmandibular implants and overdenture, while implant insertion was postponed for 30\% of those with conventional dentures: these patients could opt for implants after 1 year.

In patients with mandibles of 16-25 mm height, implant loss was 17\% for 30 overdentures on 2 endosseous implants, while in $11 \%$ of 27 who received vestibuloplasty and complete denture and in 30\% of those with conventional dentures implant therapy was postponed. The debility of many patients was shown by 13 dying during follow-up.

\section{IMPLANT DENTISTRY}

\section{A long-term follow-up of 76 Brånemark single-tooth implants}

Haas R, Polak C et al. Clin Oral Imp/ Res 2002; 13: 38-43

Failure was about 10\%, and most occurred within 2 years, with a surprising trend towards greater mandibular loss.

This study followed 97\% of a group of 76 implants (59 maxillary) in 71 patients for 4-10 yrs (mean 5.5). This is a lower drop-out rate than in other studies. Eleven implants were inserted immediately after extraction, 17 were delayed to 6-8 weeks postextraction and 48 were placed in normal edentulous ridge tissues. Guided bone regeneration was added to 14 implant insertions and hydroxyapatite augmentation to 5 , and both these adjuncts were used in one case.

Kaplan-Meier survival probabilities were 96\% for the maxilla and $80 \%$ for the mandible after 120 months (NS). Five implants were lost, 4 within 2 years. With 12 implants, abutment screws loosened during the study, but this was resolved in 5 where a electronic torque controller was applied at $32 \mathrm{Ncm}$. Mean periimplant bone loss was $1.8 \mathrm{~mm}$ in the maxilla and $1.3 \mathrm{~mm}$ in the mandible, and 15 implants showed more than $2 \mathrm{~mm}$ bone loss. In $74 \%$ of sites healthy soft tissues were maintained.

\section{PAEDIATRIC DENTISTRY}

\section{Placement and replacement of restorations in primary teeth \\ Mjör IA, Dahl JE et al. Acta Odontol Scand 2002; 60: 25-28}

Caries was the main reason for replacement.

Data from 2 surveys, of 2040 primary tooth restorations (14\% replacements of failed restorations) in 1996, and of 241 (9\%) in 2001 were included in this study. Data from the 2 surveys were not significantly different and were combined for 271 replacements.

Secondary caries was the main reason for replacement, followed by restoration fracture. In 48 replacements of amalgam restorations, these reasons accounted respectively for 53\% and 24\%, in 117 conventional glass ionomers, for $48 \%$ and $29 \%$, and in 93 resin-modified glass ionomers, for $50 \%$ and $13 \%$. There were too few restorations in other materials for them to be included in the analysis.

Median age of amalgams was 3 yrs, significantly higher than 2yrs for tooth-coloured restorations. The authors considered this effect nullified any possible cariostatic influence of fluoride release from glass ionomer materials. 